\title{
TRACIAL MOMENT PROBLEMS ON HYPERCUBES
}

\author{
CONG TRINH LE
}

Abstract. In this paper we introduce the tracial $K$-moment problem and the sequential matrixvalued $K$-moment problem and show the equivalence of the solvability of these problems. Using a Haviland's theorem for matrix polynomials, we solve these $K$-moment problems for the case where $K$ is the hypercube $[-1,1]^{n}$.

Mathematics subject classification (2010): 44A60, 30E05, 13J30, 47A57, 11E25.

Keywords and phrases: Moment problem, matrix polynomial, moment functional, moment sequence, hypercube.

\section{REFERENCES}

[1] S. BuRgdorf AND I. KLEP, The truncated tracial moment problem, J. Oper. Theory 68 (1) (2012), $141-163$.

[2] S. Burgdorf, I. KleP And J. Povh, The tracial moment problem and trace-optimization of polynomials, Math. Prog. 137, Issue 1-2 (2013), 557-578.

[3] J.Cimprič, A. Zalar, Moment problems for operator polynomials, J. Math. Anal. Appl. 401 (1) (2013), 307-316.

[4] H. Dette And W.J. Studden, Matrix measures, moment spaces and Favard's theorem for the interval $[0,1]$ and $[0,+\infty)$, Linear Algebra Appl. 345 (2002), 169-193.

[5] D. P. Kimsey, Matrix-valued moment problems, Ph. D. dissertation, Drexel University, Philadelphia, PA, 2011.

[6] D. P. Kimsey And H. J. Woerdeman, Truncated matrix-valued moment problems on $\mathbb{R}^{d}, \mathbb{C}^{d}$, and $\mathbb{T}^{d}$, Trans. Amer. Math. Soc. 365 (10) (2013), 5393-5430.

[7] C.-T. LÊ, T. H. B. DU, Handelman's Positivstellensatz for polynomial matrices positive definite on polyhedra, Positivity 22 (3) (2018), 449-460.

[8] C. W. SCHERER, C. W. J. HoL, Matrix sum-of-squares relaxations for robust semi-definite programs, Math. Program. 107 no. 1-2, Ser. B (2006), 189-211.

[9] K. SCHMÜDGEN, The K-moment problem for compact semi-algebraic sets, Math. Ann. 289 (1) (1991), 203-206.

[10] K. SCHMÜDGEN, The moment problem, Springer, 2017. 